\title{
Systematic Study on the Discharge Product of Pt-Based Lithium Oxygen Batteries
}

\author{
Feng Wu, ${ }^{a b \uparrow}$ Yi Xing, ${ }^{a c \rrbracket}$ Xuanxuan $B i,{ }^{c d \uparrow}$ Yifei Yuan, ${ }^{c e}$ Hsien-Hau Wang, ${ }^{f}$ Reza \\ Shahbazian-Yassar, ${ }^{e}$ Li Li, ${ }^{a b}$ Renjie Chen, ${ }^{* a b}{ }^{\text {Jun }} \mathrm{Lu}^{*^{c}}$ andKhalil Amine ${ }^{c}$
}

a Beijing Key Laboratory of Environmental Science and Engineering, School of Material Science \& Engineering, Beijing Institute of Technology, Beijing 100081, PR China

b Collaborative Innovation Center of Electric Vehicles in Beijing, Beijing 100081, PR China

c Chemical Science and Engineering Division, Argonne National Laboratory, 9700 S. Cass Avenue, Lemont, IL 60439, USA

$d$ Department of Chemistry and Biochemistry, The Ohio State University,100 West 18th Avenue, Columbus, $\mathrm{OH}$ 43210, USA

e Department of Materials Science and Engineering, Michigan Technological University, 1400 Townsend Drive, Houghton, MI 49931, USA

f Materials Science Division, Argonne National Laboratory, Argonne, IL 60439, USA

I These authors contributed equally to this work.

*Corresponding authors: junlu@anl.gov(J.Lu) and chenrj@bit.edu.cn (R. Chen)

ABSTRACT: Lithium oxygen batteries have attracted much attention due to the high theoretical energy density. However, they suffer a large overpotential during oxygen evolution process and thus catalysts play a vital role in the reaction. Here, we systematically explored the influence of Pt-based nanoparticle catalysts on the discharge product $\mathrm{Li}_{2} \mathrm{O}_{2}$. Because of the superior electrical conductivity and the strong binding with oxygen, Pt-based nanoparticles serve as active sites which are favorable for the growth of toroidal $\mathrm{Li}_{2} \mathrm{O}_{2}$. We also found that the content and composition of Pt-based nanoparticle catalysts exert a significant influence on the electrochemical performance of lithiumoxygen batteries. The discharge products are composed of crystalline $\mathrm{Li}_{2} \mathrm{O}_{2}$ 
and oxygen-rich $\mathrm{LiO}_{2}$ characterized by high-energy X-ray diffraction and Raman. Atomic force microscopy further provides detailed information of the particle size and surface roughness. The loading of Pt catalysts determines the phase and size of $\mathrm{Li}_{2} \mathrm{O}_{2}$ on the discharged electrode surface. This study will be beneficial for the optimization of Pt-based catalysts used in non-aqueous lithiumoxygen batteries.

Keywords: Lithium- $\mathrm{O}_{2}$ batteries; Pt-based catalysts; $\mathrm{Ru}$; Discharge products $\mathrm{Li}_{2} \mathrm{O}_{2}$; Atomic Force Microscopy

\section{Introduction}

Rechargeable non-aqueous lithium oxygen $\left(\mathrm{Li}-\mathrm{O}_{2}\right)$ batteries are considered one of the most promising systems to meet the current stringent requirements for power sources because of their extremely high theoretical specific energy, reaching to ten times higher than that of metal-ion batteries.[1-4] However, their performance has been largely limited by the high charge overpotential, resulting in a low round-trip efficiency and side reactions. The excessive charge potential is primarily induced by the undesirable discharge product $\mathrm{Li}_{2} \mathrm{O}_{2}$, which accumulates on the surface of the cathode during discharge. To reduce the large overpotential, common strategies include optimizing the porous and conductive supporting carbon materials and applying catalysts for oxygen evolution reaction (OER) in the air electrode. $[1,5,6]$

Recent works have shown that catalysts could greatly reduce the charge voltages of $\mathrm{Li}-\mathrm{O}_{2}$ batteries. Great efforts have been devoted to developing cathode catalysts, such as noble metals, alloys, metal oxides, and functional doped-carbon materials.[7-14]Among the catalysts, platinum based catalysts show outstanding catalytic activity, attracting much attention of researchers.[7, 15-19] Li et al.[18] fabricated the self-standing composites of Pt/CNTs supported on nickel foam as the cathode for lithium- $\mathrm{O}_{2}$ batteries. The high catalytic activity of Pt nanoparticles and the unique binder-free architecture endows $\mathrm{Li}_{-} \mathrm{O}_{2}$ batteries with a high specific capacity, decent rate capability, and good cycle stability. Yang group[16, 19] examined the OER activity of Pt-Au particles supported on carbon as a cathode in lithium- $\mathrm{O}_{2}$ batteries. The charge voltages ranged from 3.4 to $3.8 \mathrm{~V}$, which were slightly lower than that obtained with Pt. These studies prove that the noble metal catalysts are beneficial to achieving high energy density in $\mathrm{Li}^{-} \mathrm{O}_{2}$ batteries. 
Although it has been demonstrated that the bulk $\mathrm{Li}_{2} \mathrm{O}_{2}$ could electrocatalytically be decomposed at the presence of catalysts[20], the role of Pt based catalysts has not been fully understood. The crystal structure and morphologyof the discharge product $\left(\mathrm{Li}_{2} \mathrm{O}_{2}\right)$ have great impacts on the cell performance. Prior researches[21-24] indicated that noble metal catalysts contribute to the formation of poorly crystallized $\mathrm{Li}_{2} \mathrm{O}_{2}$. The amorphous $\mathrm{Li}_{2} \mathrm{O}_{2}$, for example, improves the reversibility during charge/discharge because it has lower charge overpotential than large toroidal or dish-like products. Therefore, it is important to examine the correlation between catalysts and the discharge products.

In this study, we investigate the effect of a series of Pt-based nanoparticle catalysts with different contents and compositions on $\mathrm{Li}_{-} \mathrm{O}_{2}$ batteries. With multiple techniques such as atomic force microscopy (AFM), scanning electron microscopy (SEM), high-energy X-ray diffraction (XRD), and Raman spectroscopy, the discharge products on the surface of electrodes were carefully examined. As a comparison, $\mathrm{Ru}$ is also introduced to the Pt system as Pt-Ru catalysts to be applied in $\mathrm{Li}_{-} \mathrm{O}_{2}$ batteries. Compared with the monometal catalyst, $\mathrm{Ru}$ in $\mathrm{Pt}-\mathrm{Ru}$ catalyst contributes to the production of more poorly crystalline $\mathrm{Li}_{2} \mathrm{O}_{2}$ on the surface, especially during the initial discharge stage. The Pt-Ru exhibits superior OER catalytic activity than the Pt noble metal, as determined by an electrochemical test. We also confirm that the content and size of Pt-based nanoparticle catalysts result in different morphologies (diameter and thickness) of toroidal discharge products, as observed by the techniques of SEM and AFM.

\section{Experimental Section}

\subsection{Preparation and Electrochemical Evaluation of Pt/C Cathodes}

The Pt-based catalysts studied here are $10 \mathrm{wt} \% \mathrm{Pt}, 40 \mathrm{wt} \% \mathrm{Pt}$, and $20 \mathrm{wt} \% \mathrm{Pt} / 10 \mathrm{wt} \% \mathrm{Ru}$ on Vulcan carbon (XC-72), all of which were purchased from Premetek (Wilmington in the state of Delaware, USA). The preparation of cathode was as follow: a mixture containing $80 \mathrm{wt} \%$ of Pt-based catalysts on Vulcan carbon and $20 \mathrm{wt} \%$ ofpolyvinylidenefluoride (PVDF) was well mixed by grinding and then pressed onto carbon paper which served as a current collector. Then the cathodes were dried at $80^{\circ} \mathrm{C}$ under vacuum for $24 \mathrm{~h}$ before use. The loading density of active material was approximately $1.0 \mathrm{mg} / \mathrm{cm}^{2} .1 \mathrm{M}$ lithium trifluoromethanesulfonate $\left(\mathrm{LiCF}_{3} \mathrm{SO}_{3}\right)$ in tetraethyleneglycol dimethyl ether (TEGDME) was employed as electrolyte, which was prepared in anargon(Ar) filled glove box at water and oxygen contents below $0.1 \mathrm{ppm}$. 
The electrochemical test was carried out using a Swagelok-type cell, composed of a lithium metal tablet as anode, one slice of glass fiber separator (Fisher Scientific, Pittsburgh in the state of Pennsylvania, USA), $1 \mathrm{~mL}$ electrolyte, and a prepared cathode (11 mm diameter).The cells were sealed except for the Al grid window, which exposed the porous cathode to pure oxygen. The batterieswere also assembledin the argon filled glove box. Before measurements, the batteries were flushed with pure oxygen for $30 \mathrm{~min}$. Then each measurement started after a $5 \mathrm{~h}$ open circuit potential step to assure equilibrium in the cell.The electrochemical measurements were carried out using a MACCOR cycler. The discharge-charge performance was conducted in the voltage range of $2.0-4.5 \mathrm{~V}$ or at limited capacities $(500 \mathrm{mAh} / \mathrm{g}, 1000 \mathrm{mAh} / \mathrm{g})$ at a constant current of $100 \mathrm{~mA} / \mathrm{g}$. We normalized the observed capacity by the weight of the carbon and catalyst for comparison in this study.

\subsection{Characterization}

Electron microscopy.Field-emission SEM (Hitachi S-4700) was employed to determine the morphology of the discharge product $\mathrm{Li}_{2} \mathrm{O}_{2}$. Before the measurements, the discharged cathode was removed from the cell and washed with dimethyl glycol solvent in a glove box. JEOL JEM-ARM200CF with a $200 \mathrm{kV}$ cold field-emission source was employed to evaluate the morphology and particle size of the Pt and Pt-Ru catalysts. An Oxford X-max 100TLE windowless SDD X-ray detector was used for chemical composition analysis. To prepare the TEM specimens, a dilute suspension was prepared by ultrasonically dispersing the $\mathrm{Pt}$ catalyst in isopropanol alcohol for $5 \mathrm{~min}$, and a drop of the suspension was placed onto a copper grid and dried.

AFM.The electrodes dissembled from the lithiumoxygen batteries after discharge were characterized by multimode AFM (Bruker Corporation, Digital Instrument, Controller IV) in an Ar-filled glovebox. The particle size and surface roughness $\left(\mathrm{R}_{\mathrm{q}}\right)$ of $\mathrm{Li}_{2} \mathrm{O}_{2}$ were obtained by the software V720. $R_{q}$ is the standard deviation of the $\mathrm{Z}$ values within the box cursor and is calculated as:

$$
R q=\sqrt{\sum \frac{(Z i)^{2}}{N}}
$$

where $\mathrm{Z}_{\mathrm{i}}$ is the current $\mathrm{Z}$ value and $\mathrm{N}$ is the number of points within the box cursor. 
High-energy XRD. The cathode laminates after discharge were characterized by high-energy synchrotron XRD to determine the formation of $\mathrm{Li}_{2} \mathrm{O}_{2}$, which was carried out at the 11-ID-C beamline of the Advanced Photon Source, Argonne National Laboratory. The X-ray wavelength was $0.11798 \AA$. The samples were completely sealed by Kapton tape as a protective film in the glove box to avoid any side reactions from air. The XRD patterns were collected in transmission mode using a PerkinElmer large-area detector. The collected two-dimensional patterns were then integrated into conventional one-dimensional patterns (intensity versus $2 y$ ) for final data analysis using Fit2d software.

Raman spectra.The Raman spectra of discharged cathodes were obtained using a Renishaw 2000 or inVia microscope spectrometer with a HeNe laser at an exciting wavelength of $633 \mathrm{~nm}$. The sample was loaded inside a glove box to a gas-tight Raman cell with a glass or quartz window. The Raman spectrum collection was performed in $180^{\circ}$ reflective mode. Roughly $10 \%$ of the maximum $13 \mathrm{~mW}$ laser intensity was applied.

\section{Results and discussion}

Various Pt-based catalysts (Pt1 - 10 wt \% Pt, Pt2 - 40 wt $\%$ Pt, Pt3 - 20 wt $\%$ Pt and 10 wt $\%$ Ru on Vulcan carbon) were investigated here. Transmission electron microscopy (TEM) images show that Pt and Pt-Ru nanoparticles are uniformly distributed on graphite carbon (Figure 1a-c), and the particle size of Pt2 $(\sim 4 \mathrm{~nm})$ is apparently larger than those of Pt1 and Pt3 $(\sim 2 \mathrm{~nm})$. In such a small range, $\mathrm{Pt}$ and $\mathrm{Ru}$ atoms are distributed uniformly within individual particles, indicating the alloying of $\mathrm{Pt}$ and $\mathrm{Ru}$; these results are supported by energy-dispersive X-ray mapping (Figure $1 d-e)$. 

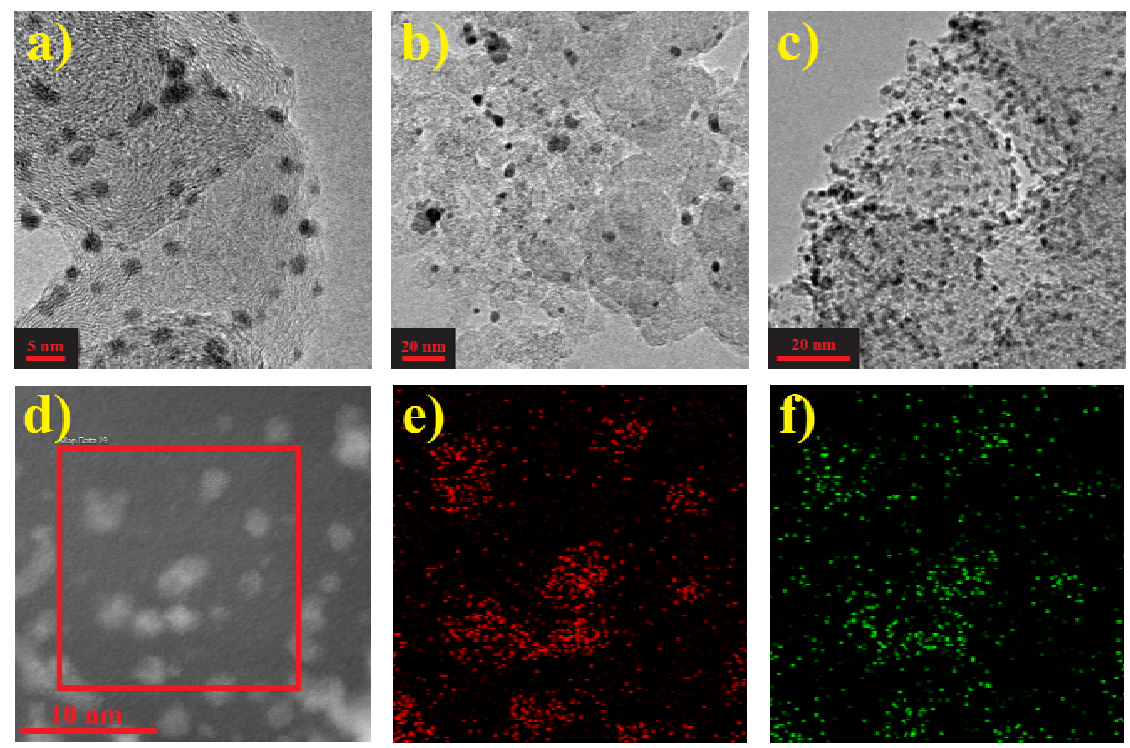

Figure 1.(a, b, c) TEM images of Pt1, Pt2, and Pt3, respectively. (d) High angle annular dark field (HAADF) image of Pt3 with the corresponding elemental mappings shown in (e) for Pt, and (f) for $\mathrm{Ru}$.

The discharge and charge profiles of Pt-based catalysts were recorded at $100 \mathrm{~mA} / \mathrm{g}$ in the voltage range of $2.2-4.5 \mathrm{~V}$ vs. $\mathrm{Li}^{+} / \mathrm{Li}$, as shown in Figure 2a. The discharge capacities of Pt1 and Pt3 electrodes are much higher than that of Pt2, and the Pt3 electrode exhibits the lowest charge overpotential. This indicates that the content and composition of Pt-based catalysts exert a noticeable influence on the electrochemical performance of $\mathrm{Li}-\mathrm{O}_{2}$ batteries. And the results show that the nanoscale Pt-based particles, distributed evenly on supporting materials, are better catalysts in $\mathrm{Li}-\mathrm{O}_{2}$ batteries than the large agglomerated ones. The deep discharged electrodes were examined by SEM as shown in Figure 2b-d. The discharge products covered on the surface of electrodes are primarily toroidal particles. However, the sizes (diameter and thickness) are different based upon loading and type of catalyst. The diameters of the toroidal discharge products of Pt2 are obviously smaller than the others. Carl's group[25] reported that the large facets of $\mathrm{Li}_{2} \mathrm{O}_{2}$ plates formed the toroidal particles and the plate spraying may be attributed to the difference in surface stress driving the evolution from disc to toroidal shapes. The Pt nanoparticle catalyst loading of Pt2 is much more than those of Pt1 and Pt3, suggesting more active sites with strong oxygen binding for discharge. Therefore, smaller toroidal discharge products are coveredon the surface of the Pt2 electrode, comparing with the other two. 

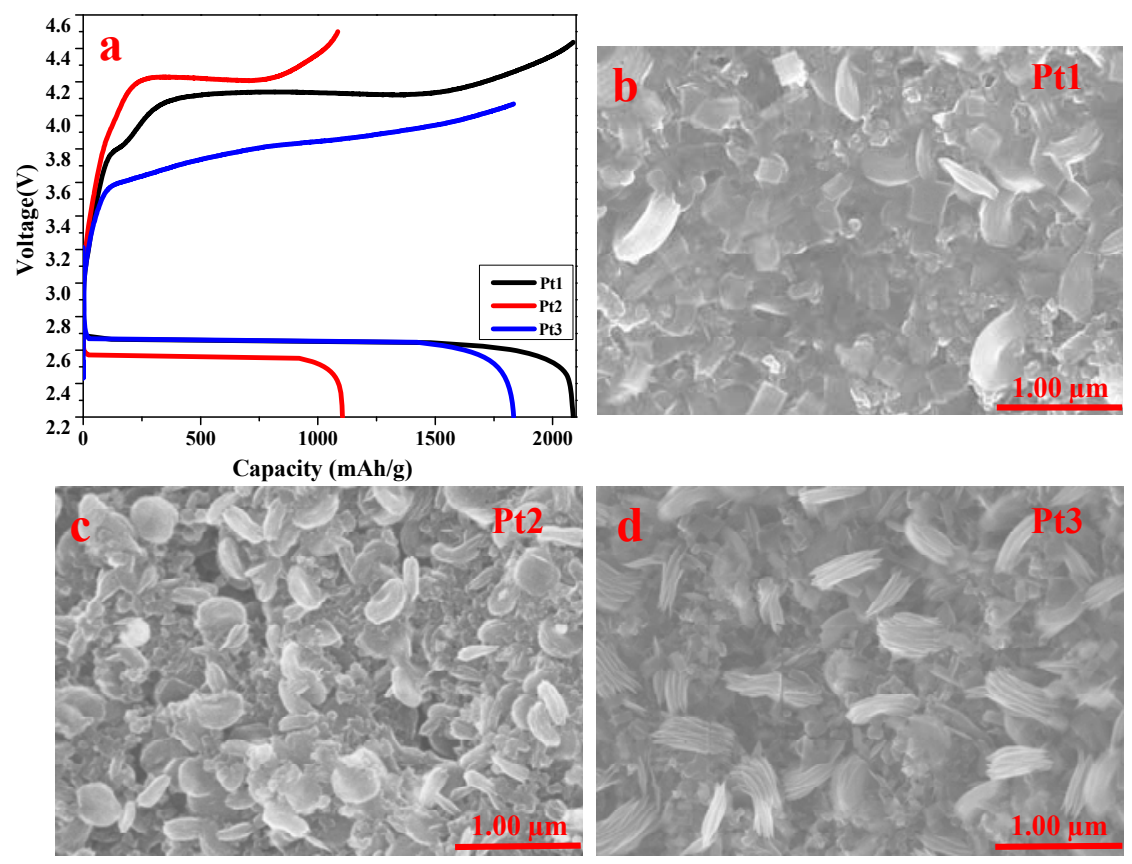

Figure 2.(a) First galvanostaticdischarge/charge curves of $\mathrm{Pt} 1, \mathrm{Pt} 2$, and $\mathrm{Pt} 3 \mathrm{at} 100 \mathrm{~mA} / \mathrm{g}$ in the voltage range of 2.2-4.5V. SEM images of electrodes discharged to $2.2 \mathrm{~V}$ at $100 \mathrm{~mA} / \mathrm{g}$ : (b) Pt1, (c) Pt2, and (d) Pt3.

To investigate the catalytic activity for OER kinetics, the first charge voltages were compared under capacity-controlled conditions at the same rate $(100 \mathrm{~mA} / \mathrm{g})$, as shown in Figure $3 \mathrm{a}-\mathrm{b}$. The mid-capacity potential (defined as the potential at half capacity,[15] $3.7 \mathrm{~V}$ ) of Pt3 is obviously lower than those of Pt1 and Pt2 (4.1 V and 4.2 V), and the onset oxidation potential of Pt3 (3.0 V) is also lower than those of Pt1 and Pt2 (both $3.2 \mathrm{~V}$ ) at a fixed capacity of $500 \mathrm{mAh} / \mathrm{g}$. All these performances indicate the superior electrocatalytic activity for OER of the Pt-Ru catalyst compared with the Pt noble metal. At the capacity limit of $1000 \mathrm{mAh} / \mathrm{g}$, the mid-capacity potential of Pt2 is barely changed, while that of Pt1 slightly shifts to $4.2 \mathrm{~V}$. Meanwhile, the mid-capacity potential of Pt3 significantly increases to $3.9 \mathrm{~V}$. The corresponding electrodes discharged with capacities of $500 \mathrm{mAh} / \mathrm{g}$ and $1000 \mathrm{mAh} / \mathrm{g}$ at current density of $100 \mathrm{~mA} / \mathrm{g}$ were investigated by SEM, Raman spectroscopy, and XRD. In Figure 4, compared with the fresh cathodes, toroidal or dish-like discharge products begin to emerge at the fixed capacity of $500 \mathrm{mAh} / \mathrm{g}$. It should be noted that the discharge productsof the Pt2 grow more quickly to the large toroidal ones than the others. When the discharge capacities reach $1000 \mathrm{mAh} / \mathrm{g}$, more toroidal discharge products are covered on the surface of the Pt2 electrode, but their sizes only slightly change. Meanwhile, the 
discharge products of Pt1 and Pt3 evolve to large toroidal shapes with many plate-like arrays. However, there are fewer discharge products on the surface of the Pt3 electrode than the others. This may imply that the different morphology evolution of discharge products results in the mid-capacity potential change, as mentioned above.
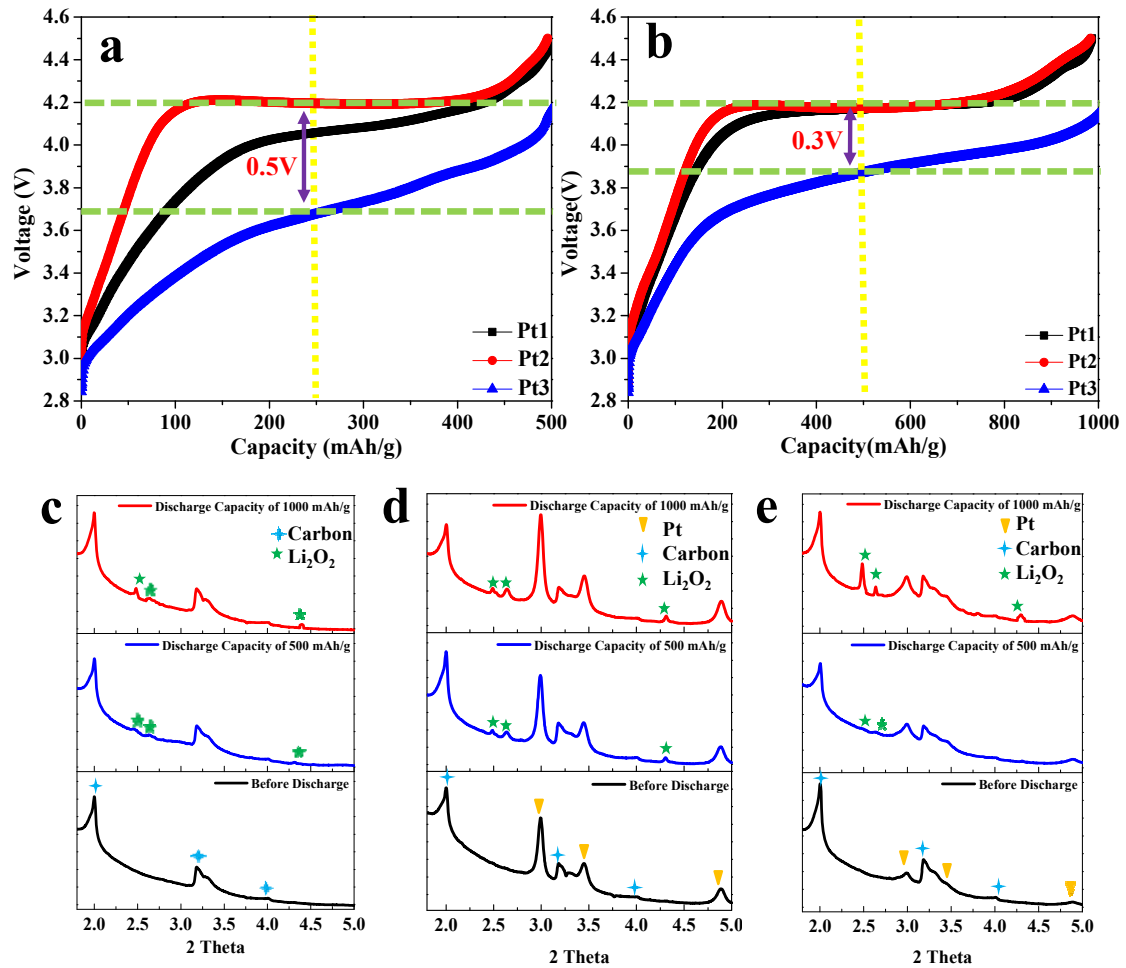

Figure 3. First galvanostatic charge curves of Pt1, Pt2, and Pt3 at $100 \mathrm{~mA} / \mathrm{g}$ with capacities of (a) $500 \mathrm{mAh} / \mathrm{g}$ and (b) $1000 \mathrm{mAh} / \mathrm{g}$. XRD spectra of electrodes discharged with different capacities at 100 mA/g current: (c) Pt1, (d) Pt2, and (e) Pt3.

The XRD and Raman spectrum characterized the discharge products at fixed discharge capacities of 500 and $1000 \mathrm{mAh} / \mathrm{g}$. The peaks from the discharged electrodes are identified as the (100), (101), and (110) peaks of $\mathrm{Li}_{2} \mathrm{O}_{2}$ according to the standard XRD histogram, [8, 26, 27] as shown in Figure 3c-e. XRD analysis confirms that the discharge products are mostly crystalline $\mathrm{Li}_{2} \mathrm{O}_{2}$. Compared with electrodes Pt1 and Pt2, the $\mathrm{Li}_{2} \mathrm{O}_{2}$ peak intensity of Pt3 is extraordinarily weaker at the fixed discharge capacity of $500 \mathrm{mAh} / \mathrm{g}$, indicating the poorly crystallized $\mathrm{Li}_{2} \mathrm{O}_{2}$ of Pt3. When the discharge capacity increases to $1000 \mathrm{mAh} / \mathrm{g}$, the $\mathrm{Li}_{2} \mathrm{O}_{2}$ peak intensity of Pt3 becomes much stronger. This result suggests more crystalline $\mathrm{Li}_{2} \mathrm{O}_{2}$ emerge on the surface of Pt3 electrode at the fixed discharge capacity of $1000 \mathrm{mAh} / \mathrm{g}$, which may be the reason that the mid-capacity potential becomes larger with the capacity increasing in Pt3 system. In the Raman 
spectra of the discharged electrodes (Figure 5), the peaks near $1600 \mathrm{~cm}^{-1}$ and $1340 \mathrm{~cm}^{-1}$ are from the graphite ( $\mathrm{G}$, internal phenyl ring stretch) band and disordered graphitic islands (D band), respectively.[28, 29] The band located near $1123 \mathrm{~cm}^{-1}$ is a signature of $\mathrm{LiO}_{2}$-like components, and the band near $1505 \mathrm{~cm}^{-1}$ has been identified to come from strong interactions between $\mathrm{LiO}_{2}$ and a graphite carbon surface.[20,30,31] Accompanied by the capacity increase, the relative peak intensities of $\mathrm{LiO}_{2}$ become stronger because of the accumulation of discharge products. We can therefore conclude that the toroidal discharge products of Pt1 and Pt2 are made up of $\mathrm{LiO}_{2}$-like species and $\mathrm{Li}_{2} \mathrm{O}_{2}$ components, as reported before.[31] However, we also surmise that the $10 \mathrm{wt} \%$ $\mathrm{Ru}$ in Pt-Ru may result in the different shape evolution of discharge products between Pt3 and the others. Recently, numerous studies have reported the role of Ru-based catalysts in transforming the morphology and structure of discharge products in lithium- $\mathrm{O}_{2}$ batteries. $[9,21,24,32-34]$ The $\mathrm{Ru}$-based catalysts promote the formation of $\mathrm{Li}_{2} \mathrm{O}_{2}$ films (lithium-deficient $\mathrm{Li}_{2-\mathrm{x}} \mathrm{O}_{2}$ ) with poor crystal structure on the surface of the electrode, and lithium-deficient $\mathrm{Li}_{2-\mathrm{x}} \mathrm{O}_{2}$ have been reported to have much lower overpotentials than large toroidal crystal $\mathrm{Li}_{2} \mathrm{O}_{2}$ during charging.[21, 23, 25, 35, 36] Therefore, the lower charge overpotential of the Pt-Ru catalyst compared with the Pt-only system is caused by the introduction of Ru nanoparticles.Furthermore, the capacity verse cycle number plots of $\mathrm{Li}-\mathrm{O}_{2}$ batteries with Pt1, Pt2 and Pt3 catalysts are shown in Figure 6. The results demonstrate that the $\mathrm{Li}-\mathrm{O}_{2}$ battery with Pt-Ru catalyst shows better cycling performance than the others, indicating its better stability. 


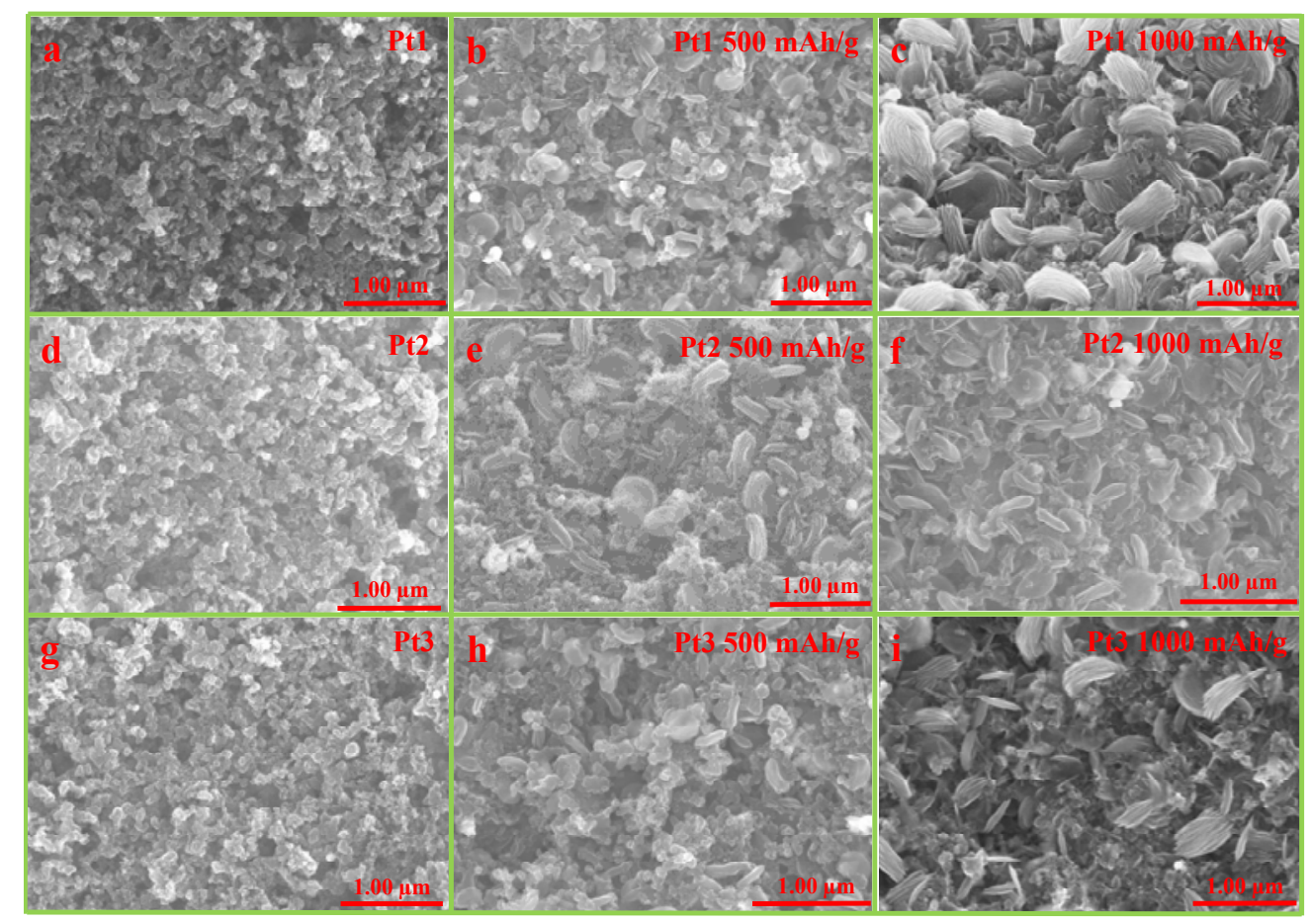

Figure 4. SEM images of Pt1, Pt2, and Pt3 electrodes: (a, d, g) pristine electrodes before cycling, (b, e, h) after discharge with $500 \mathrm{mAh} / \mathrm{g}$ capacityat $100 \mathrm{~mA} / \mathrm{g}$ current, and (c, f, i) after discharge with $1000 \mathrm{mAh} / \mathrm{g}$ capacity at $100 \mathrm{~mA} / \mathrm{g}$ current. Red scale bar $=1 \mu \mathrm{m}$.
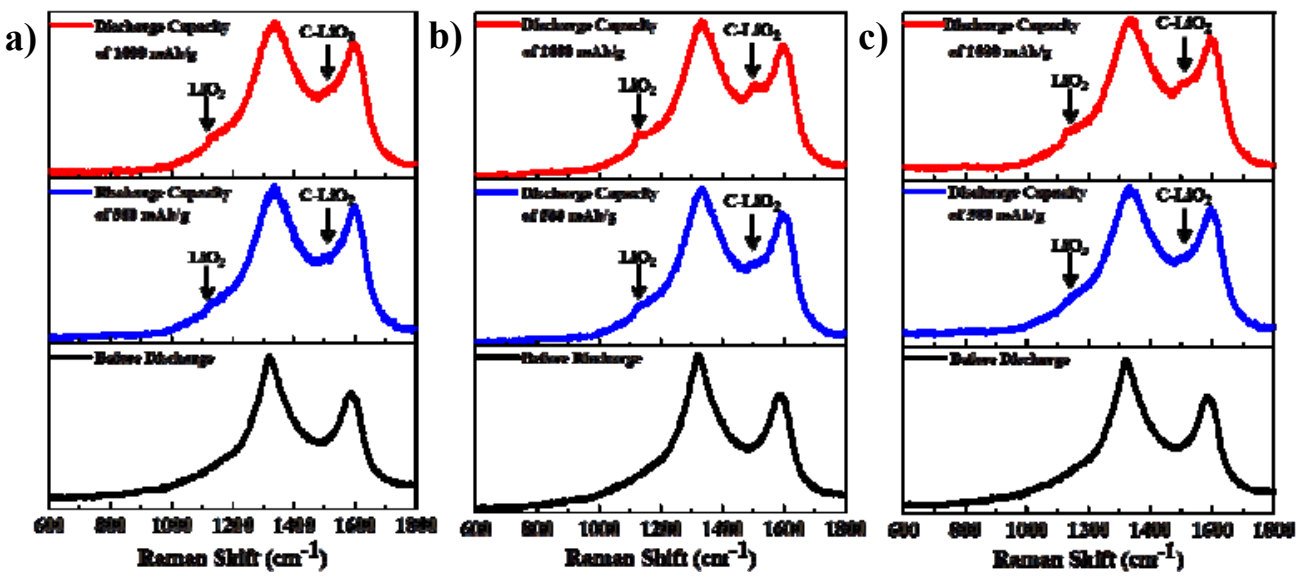

Figure 5. Raman spectra of electrodes discharged with different capacities at $100 \mathrm{~mA} / \mathrm{g}$ current: (a) Pt1, (b)Pt2, and (c)Pt3.

To provide straightforward and detailed information, we observed the discharge products using AFM (Figure 7). Through the AFM images (tapping mode, providing topography, and phase images), we can clearly see that the toroidal discharge particles are composed of arrays of plate-like products, especially in Figure $7 \mathrm{~b}$. The thicknesses of the $\mathrm{Li}_{2} \mathrm{O}_{2}$ plates are all in the range 
of $50-150 \mathrm{~nm}$. The diameters and thicknesses of the toroidal particles of Pt1 and Pt3 are around $500 \mathrm{~nm}$ and $350 \mathrm{~nm}$, respectively, while those of Pt2 are approximately $250 \mathrm{~nm}$ and $250 \mathrm{~nm}$, respectively. Meanwhile, the surface roughness $\left(\mathrm{R}_{\mathrm{q}}\right)$ of the $\mathrm{Li}_{2} \mathrm{O}_{2}$ of Pt1 and Pt3 is approximately $25 \mathrm{~nm}$, while that of Pt2 is approximately $15 \mathrm{~nm}$, further demonstrating the difference in morphology. The surface roughness implies that the toroidal $\mathrm{Li}_{2} \mathrm{O}_{2}$ of $\mathrm{Pt} 2$ is composed of fewer layers of plate-like $\mathrm{Li}_{2} \mathrm{O}_{2}$ crystallites than the others.

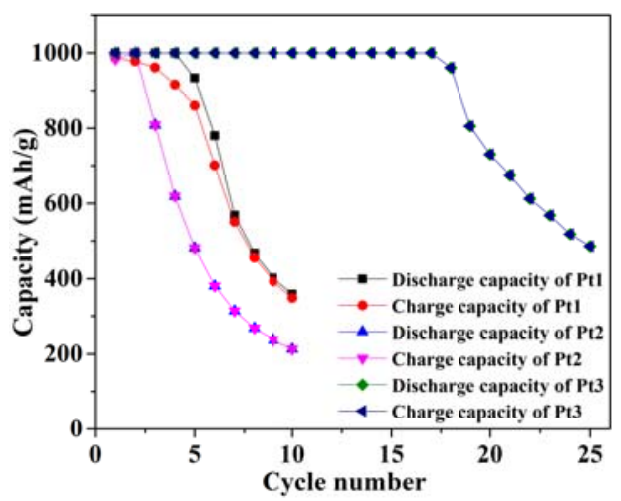

Figure 6.The discharge and charge capacity versus cycle number of lithium- $\mathrm{O}_{2}$ batteries with Pt1, Pt2 and Pt3 as cathodes at current densities of $100 \mathrm{~mA} / \mathrm{g}$ by curtailing the capacity to $1000 \mathrm{mAh} / \mathrm{g}$ in the voltage range of $2.2-4.5 \mathrm{~V}$.

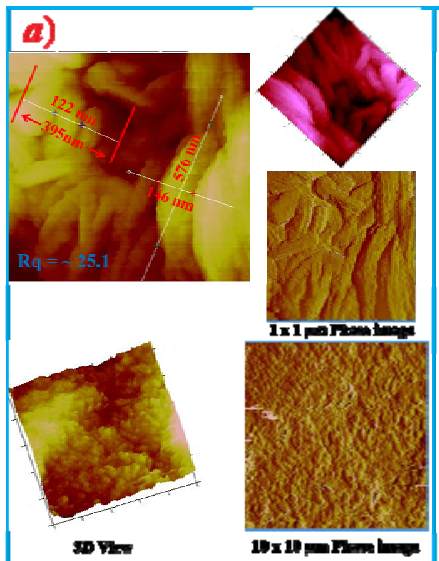

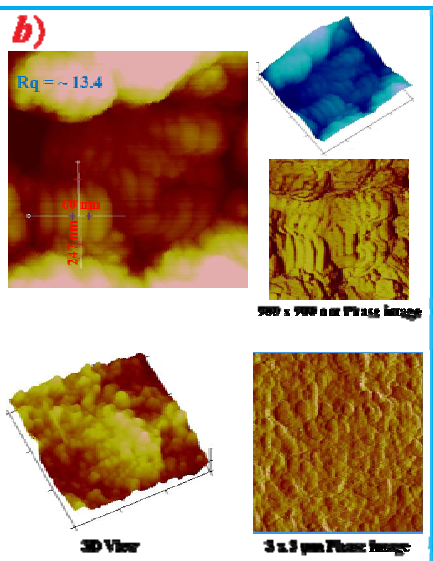

D ver c)
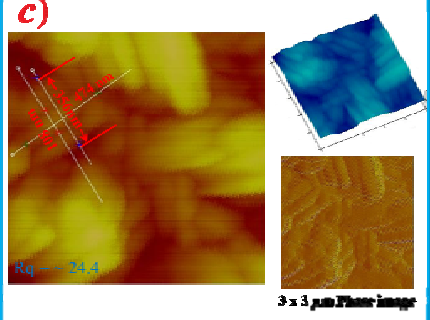

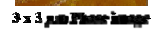

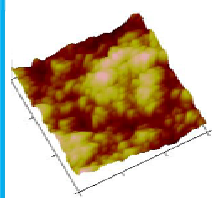

SI ที

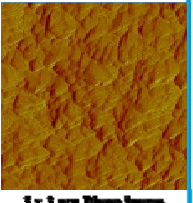

Figure 7. AFM images of electrodes discharged at $100 \mathrm{~mA} / \mathrm{g}$ current: (a) Pt1, (b) Pt2, and (c) Pt3.

\section{Conclusion}

Through the characterization and discussion provided above, we can conclude that the content and composition of Pt-based catalysts exert a significant influence on the morphology and structure of the discharge product $\mathrm{Li}_{2} \mathrm{O}_{2}$. The Pt-based nanoparticles, as active sites, are favourable 
for the growth of toroidal $\mathrm{Li}_{2} \mathrm{O}_{2}$ because of their strong binding with oxygen. The content and the size of Pt nanoparticles also affect the electrochemical performance, and the nanoscale Pt particles, distributed evenly on supporting materials, are better catalysts in lithium- $\mathrm{O}_{2}$ batteries than the large agglomerated ones. Compared with pristine Pt nanoparticle catalysts, the mid-capacity charge voltage could be reduced when Ru is added to the noble metal Pt as a Pt-Ru catalyst, which is attributed to the role of $\mathrm{Ru}$ in promotion of poorly crystallized $\mathrm{Li}_{2} \mathrm{O}_{2}$ discharge products. The AFM results provide more detailed information about the particle size and surface roughness of the discharge product $\mathrm{Li}_{2} \mathrm{O}_{2}$, which is a new characterization method applied in lithium- $\mathrm{O}_{2}$ batteries. This study will contribute to the adoption and optimization of Pt-based catalysts used in non-aqueous lithium- $\mathrm{O}_{2}$ batteries.

\section{Acknowledgements}

This work was supported by the U.S. Department of Energy under Contract DE-AC0206CH11357 with the main support provided by the Vehicle Technologies Office, Department of Energy (DOE) Office of Energy Efficiency and Renewable Energy (EERE). This work was also supported by Major achievements Transformation Project for Central University in Beijing, the National Natural Science Foundation of China (21373028), National Key Program for Basic Research of China (2015CB251106) and Beijing Science and Technology Project (D151100003015001). The authors acknowledge the use of the Advanced Photon Source (APS) and the Center for Nanoscale Materials (CNM) that are supported by the U. S. Department of Energy, Office of Science, Office of Basic Energy Sciences, under Contract No. DE-AC02-06CH11357.R. Shahbazian-Yassar and Y. Yuan acknowledge the funding from NSF DMR-1620901 for the microscopy efforts. Y. Yuan was also partially supported via subcontract No. 4J-30361-0017A.

\section{References}

[1] J. Lu, L. Li, J.-B. Park, Y.-K. Sun, F. Wu, K. Amine, Chemical Reviews, 114 (2014) $5611-5640$.

[2] J. Lu, Y. Jung Lee, X. Luo, K. Chun Lau, M. Asadi, H.-H. Wang, S. Brombosz,J. Wen, D. Zhai, Z. Chen, D.J. Miller, Y. Sub Jeong, J.-B. Park, Z. Zak Fang,B. Kumar, A. Salehi-Khojin, Y.-K. Sun, 
L.A. Curtiss, K. Amine, Nature 529 (2016)377-382

[3] Y. Meng, T. Yu, S. Zhang, C. Deng, Journal of Materials Chemistry A, 4 (2016) 1624-1631.

[4] B. Lin, Q. Li, B. Liu, S. Zhang, C. Deng, Nanoscale, 8 (2016) 8178-8188.

[5] M.D. Bhatt, H. Geaney, M. Nolan, C. O'Dwyer, Physical Chemistry Chemical Physics, 16 (2014) 12093-12130.

[6] R. Black, B. Adams, L.F. Nazar, Advanced Energy Materials, 2 (2012) 801-815.

[7] B.G. Kim, H.-J. Kim, S. Back, K.W. Nam, Y. Jung, Y.-K. Han, J.W. Choi, Sci. Rep., 4 (2014).

[8] J. Lu, Y. Lei, K.C. Lau, X. Luo, P. Du, J. Wen, R.S. Assary, U. Das, D.J. Miller, J.W. Elam, H.M. Albishri, D.A. El-Hady, Y.-K. Sun, L.A. Curtiss, K. Amine, Nat Commun, 4 (2013).

[9] B. Sun, X. Huang, S. Chen, P. Munroe, G. Wang, Nano Letters, 14 (2014) 3145-3152.

[10] L. Jin, L. Xu, C. Morein, C.-h. Chen, M. Lai, S. Dharmarathna, A. Dobley, S.L. Suib, Advanced Functional Materials, 20 (2010) 3373-3382.

[11] W. Yang, J. Salim, C. Ma, Z. Ma, C. Sun, J. Li, L. Chen, Y. Kim, Electrochemistry Communications, 28 (2013) 13-16.

[12] J. Shui, F. Du, C. Xue, Q. Li, L. Dai, ACS Nano, 8 (2014) 3015-3022.

[13] Z. Zhang, J. Bao, C. He, Y. Chen, J. Wei, Z. Zhou, Advanced Functional Materials, 24 (2014) 6826-6833.

[14] G. Wu, N.H. Mack, W. Gao, S. Ma, R. Zhong, J. Han, J.K. Baldwin, P. Zelenay, ACS Nano, 6 (2012) 9764-9776.

[15] J. Cao, S. Liu, J. Xie, S. Zhang, G. Cao, X. Zhao, ACS Catalysis, 5 (2015) 241-245.

[16] J.R. Harding, Y.-C. Lu, Y. Tsukada, Y. Shao-Horn, Physical Chemistry Chemical Physics, 14 (2012) 10540-10546.

[17] B.K. Ko, M.K. Kim, S.H. Kim, M.A. Lee, S.E. Shim, S.-H. Baeck, Journal of Molecular Catalysis A: Chemical, 379 (2013) 9-14.

[18] J. Li, Y. Zhao, M. Zou, C. Wu, Z. Huang, L. Guan, ACS Applied Materials \& Interfaces, 6 (2014) 12479-12485.

[19] Y.-C. Lu, Z. Xu, H.A. Gasteiger, S. Chen, K. Hamad-Schifferli, Y. Shao-Horn, Journal of the American Chemical Society, 132 (2010) 12170-12171.

[20] J. Yang, D. Zhai, H.-H. Wang, K.C. Lau, J.A. Schlueter, P. Du, D.J. Myers, Y.-K. Sun, L.A. Curtiss, K. Amine, Physical Chemistry Chemical Physics, 15 (2013) 3764-3771. 
[21] E. Yilmaz, C. Yogi, K. Yamanaka, T. Ohta, H.R. Byon, Nano Letters, 13 (2013) 4679-4684.

[22] R. Black, J.-H. Lee, B. Adams, C.A. Mims, L.F. Nazar, Angewandte Chemie, 125 (2013)

410-414.

[23] J.-J. Xu, Z.-L. Wang, D. Xu, L.-L. Zhang, X.-B. Zhang, Nat Commun, 4 (2013).

[24] F. Li, D.-M. Tang, Y. Chen, D. Golberg, H. Kitaura, T. Zhang, A. Yamada, H. Zhou, Nano Letters, 13 (2013) 4702-4707.

[25] R.R. Mitchell, B.M. Gallant, Y. Shao-Horn, C.V. Thompson, The Journal of Physical Chemistry Letters, 4 (2013) 1060-1064.

[26] J. Kang, O.L. Li, N. Saito, Journal of Power Sources, 261 (2014) 156-161.

[27] Y. Lei, J. Lu, X. Luo, T. Wu, P. Du, X. Zhang, Y. Ren, J. Wen, D.J. Miller, J.T. Miller, Y.-K. Sun, J.W. Elam, K. Amine, Nano Letters, 13 (2013) 4182-4189.

[28] F. Negri, C. Castiglioni, M. Tommasini, G. Zerbi, The Journal of Physical Chemistry A, 106 (2002) 3306-3317.

[29] E. Riedo, E. Magnano, S. Rubini, M. Sancrotti, E. Barborini, P. Piseri, P. Milani, Solid State Communications, 116 (2000) 287-292.

[30] D. Zhai, H.-H. Wang, K.C. Lau, J. Gao, P.C. Redfern, F. Kang, B. Li, E. Indacochea, U. Das, H.-H. Sun, H.-J. Sun, K. Amine, L.A. Curtiss, The Journal of Physical Chemistry Letters, 5 (2014) 2705-2710.

[31] D. Zhai, H.-H. Wang, J. Yang, K.C. Lau, K. Li, K. Amine, L.A. Curtiss, Journal of the American Chemical Society, 135 (2013) 15364-15372.

[32] B. Sun, P. Munroe, G. Wang, Sci. Rep., 3 (2013).

[33] H.-G. Jung, Y.S. Jeong, J.-B. Park, Y.-K. Sun, B. Scrosati, Y.J. Lee, ACS Nano, 7 (2013) 3532-3539.

[34] Z. Jian, P. Liu, F. Li, P. He, X. Guo, M. Chen, H. Zhou, Angewandte Chemie International Edition, 53 (2014) 442-446.

[35] B.D. Adams, C. Radtke, R. Black, M.L. Trudeau, K. Zaghib, L.F. Nazar, Energy \& Environmental Science, 6 (2013) 1772-1778.

[36] B.M. Gallant, D.G. Kwabi, R.R. Mitchell, J. Zhou, C.V. Thompson, Y. Shao-Horn, Energy \& Environmental Science, 6 (2013) 2518-2528. 